\title{
Applications and Prospects of Fiber Reinforced Concrete in Industrial Floors
}

\author{
Hesham Alsharie \\ Civil Engineering Department, Faculty of Engineering, Jerash University, Jerash, Jordan \\ Email: dr.sharie@yahoo.com
}

Received 7 April 2015; accepted 16 May 2015; published 21 May 2015

Copyright (C) 2015 by author and Scientific Research Publishing Inc.

This work is licensed under the Creative Commons Attribution International License (CC BY). http://creativecommons.org/licenses/by/4.0/

(c) (i) Open Access

\begin{abstract}
Upon the view of this work, industrial floor is a vital structure due to its relation to quality of production, labor comfort, and human health. Flooring costs may reach $20 \%$ of single-story building construction expenditure, and the consumption of concrete for floors may come to $40 \%-50 \%$ of the total size of concrete. Thereby, the efficient design of floor will reduce materials consumption and labor, and will increase the endurance of the floor. Fiber reinforcement reduces the thickness of the subfloor about $20 \%-30 \%$, hence enabling to reduce the consumption of cement and fillers. The use of fiber meshes will enable to save $30 \%-40 \%$ of steel. Despite the flexible use of fiber in concrete reinforcement saves effort and money, still fiber reinforced concrete is lacking additional regulations in Jordan.
\end{abstract}

\section{Keywords}

Fiber, Reinforced Concrete, Industrial Floors, Jordan

\section{Introduction}

Floor is a building structure providing a surface for the production process and people's activities; its state affects the quality of products and human health. Industrial concrete floors are typically consisted of the following structural components layers, flooring, subfloor, damp proofing, and grade. Flooring is a top layer of the floor directly subjected to operational impacts. Subfloor (underlayment), a layer of the floor intended to distribute loads on the grade [1] [2].

Damp proofing is a layer of the floor to prevent wastewater and other fluids from passing through the floor, and to protect the floor from groundwater. Grade is a natural or artificial support bearing loads transmitted from the floor. It should be noted that flooring and subfloor are often combined in a single structural component [3].

Industrial floors must meet the requirements of strength and endurance to resist tensile, compressive and 
bending forces, impacts and abrasion. Floors must be resistant to aggressive physical and chemical factors. In addition, floors must meet the technological requirements to be smooth but not slippery and provide a safe and convenient walking surface for people and vehicles. According to the sanitary requirements, floors in operation must be harmless for human health, i.e. not emit dust, hazardous gases or smell, and in some cases, they must provide comfortable thermal conditions. The operational requirements are also important and floors must be easy to repair and clean [4].

\section{Industrial Floors Characterization}

Industrial floor is an important structure due to its relation to quality of production, labor comfort, and human health. Flooring costs may reach $20 \%$ of single-story building construction expenses, and the consumption of concrete for floors may come to $40 \%$ - $50 \%$ of the total concrete.

Floors of industrial buildings include premises associate to industrial applications that comprise the following groups:

- Floors for general purposes;

- Floors with special requirements of cleanness, dust separation and conductivity; they must be non-sparking

- and antistatic;

- Floors with special thermal engineering requirements;

- Floors resistant to very harsh mechanical impacts;

- Special purpose floors that are resistant to high temperature or various chemical environments, including aggressive environments.

Floors of industrial buildings are conventionally divided into the following groups:

I-floors that are not intended for fixed equipment (production equipment requires installation of special foundations, and floors bear loads caused by people, vehicles and stored materials);

II-floors on which fixed equipment is installed without special requirements to the foundation deformation (emerging deformations or cracks in the subfloor do not disrupt fixed equipment operation; in case of floor repair, equipment may be relocated);

III-floors on which machines, pumps and other discrete equipment with special requirements to the foundation are installed;

IV—floors on which automated lines, flexible systems, etc. are installed;

V-floors providing damp proofing [5] [6].

\section{Strength of Floors}

Hard subfloor is the most crucial structural element of the floor; it ensures the distribution of loads on the grade. Hard subfloor must be made of concrete C20/25 at least. If the calculated tensile stress in the concrete C20/25 subfloor is lower than the estimated one, it is possible to use concrete of lower classes, but not lower than C8/10.

The thickness of the concrete subfloor is determined by means of strength calculation of operating loads and must be at least $80 \mathrm{~mm}$ for floors of residential and public buildings and not less than $100 \mathrm{~mm}$ for industrial floors. When using concrete subfloor as flooring, its estimated thickness must be increased by 20 - $30 \mathrm{~mm}$ [7].

Expansion joints should be built up in the concrete subfloor in mutually perpendicular directions spaced on 6 $12 \mathrm{~m}$. The depth of the expansion joint must be at least $40 \mathrm{~mm}$ and not less than $1 / 3$ of the thickness of the subfloor. After shrinkage, expansion joints should be sealed with a cement-sand mortar. The expansion joints in floors that coincide with the expansion joints of the building must be made up throughout the thickness of the grade.

Initial data for the calculation of the subfloor are as follows:

1) Loading circuit in the plan providing its maximum value, a size and a shape of marks on the floor and the minimum distance between the marks;

2) Values of the modulus of subgrade reaction $(\mathrm{MPa} / \mathrm{m})$ which characterizes the elastic properties of the foundation.

Net weight of the floor and loads evenly distributed over the entire area are not taken into account when calculating [6]. Depending on the location of the loads transmitted to the subfloor, simple loads and complex loads are distinguished.

The strength of the floor with a concrete subfloor is calculated in bending. When there are several simple or 
complex loads, each of them is calculated individually.

The calculation is performed by means of successive approximations. At the first stage, concrete C20/25 and a $100 \mathrm{~mm}$ subfloor are taken. Then values of concrete slab flexibility, linear bending moment and tensile stresses in the subfloor concrete are determined subsequently. If the calculated value of the tensile stress in the concrete C20/25 subfloor is lower than the estimated one, the class of concrete is reduced by one level but must be not lower than C8/10, and the calculation is repeated with the same thickness of the subfloor. If the calculated value of the tensile stress in the concrete C20/25 subfloor exceeds the estimated one, the calculation is repeated with the thickness of the subfloor being increased by $20 \mathrm{~mm}$. The calculation is performed until the value of the subfloor thickness is found to ensure that the values of tensile stresses in the subfloor concrete are lower than the estimated ones [7].

\section{Fiber Reinforcement of Industrial Floors}

With the given loads on the floor and grade characteristics, the tensile strength of the concrete is the key factor determining the subfloor thickness and, hence, the consumption of concrete to build floors. It is known that steel fiber reinforcement can significantly increase the tensile strength of concrete. In this regard, the use of fiber reinforced concrete for industrial floors construction is one of the most important ways to reduce material consumption.

Fiber reinforced concrete has been known for a long time. Basic principles of the use and calculation of steel fiber reinforced concrete structures were developed in the 1960s-70s.

The constructive idea of steel fiber reinforced concrete is that randomly distributed steel fibers are a new type of reinforcement for concrete structures in stages preceding the development of cracks and the work of the material with cracks. If there is no steel fiber, micro-cracks, as they accumulate, turn into macro-cracks and lead to the destruction of concrete or loss of such properties as water and frost resistance, resistance to aggressive impacts, etc. Steel fiber reinforcement makes the concrete matrix mortar harder and increases its tensile strength until the development of cracks in the concrete structure [8] [9].

After cracking, steel fibers dispersed along the height of the crack carry tensile stresses between its edges, thus slowing down the development of cracks. Fibers in the mouth of the crack work most efficiently. As a result, cracks develop in steel fiber reinforced concrete under high loads and have a smaller opening width than those in plain concrete. The material in operation works with a limited crack opening and has a relatively high tensile strength [9].

However, the use of fiber reinforced concrete structures in Jordan has been hampered by the lack of calculation regulations and technological standards for designing concrete formulations using steel fiber reinforcement, and the lack of experience in designing steel fiber reinforced concrete structures with regard to their real work which differs sufficiently from the work of traditional reinforced concrete structures.

Researches on steel fiber reinforced concrete can be divided into two groups. Researches of the first group focus on studying steel fiber reinforced concrete characteristics and developing steel fiber reinforced concrete; the aim of the second group of researches is to study the peculiarities of manufacturing techniques for steel fiber reinforced concrete products and structures.

The study of these issues at the present level of knowledge about the behavior of concrete composite systems will enable to improve the level of production technology, create a serious scientific basis for the development of application of steel fiber reinforced concrete with new technical capabilities. The obtained data will be the basis for the development of missing in Jordan regulations on the use of this type of concrete and the design of structures with steel fiber reinforced concrete.

When developing such documents, the following terms and definitions should be used.

- Fiber reinforced concrete is a building material consisting of fine-grained concrete (matrix) reinforced with fiber segments with the tensile strength higher than that of the concrete.

- Steel fiber reinforced concrete is the original concrete (concrete matrix) reinforced with steel fibers evenly distributed throughout its volume.

- Original concrete (concrete matrix) is structural heavy concrete based on dense fillers.

- Volume percent of fiber reinforcement is the volume of fibers per volume unit of steel reinforced concrete, in percentage points.

- Weight percent of fiber reinforcement is the ratio of weight of fibers contained in a volume unit of steel fiber 
reinforced concrete to the weight of the volume unit, in percentage points.

- Fiber reinforcement ratio is a proportion of the volume of fibers per volume unit of steel fiber reinforced concrete.

- Steel fiber reinforced concrete structures are structures made of fiber reinforced concrete or structures containing non-tensioned rod and wire reinforcement with the cross-sectional area of less certain values.

- Steel fiber reinforced concrete structures with combined reinforcement are structures made of fiber reinforced concrete with non-tensioned rod and wire reinforcement.

Steel fiber reinforced concrete is recommended for structures where the following technical advantages can be used most efficiently compared to the traditional reinforced concrete:

- Increased crack, impact, wears and frost resistance;

- Reduced shrinkage and creep;

- Possibility to use more efficient design solutions without rod or mesh distribution and transverse reinforcement, etc.;

- Reduction of labor, increased degree of mechanization, and automation of the production of reinforced concrete structures.

Some recommendations should be developed on the basis of a series of researches of physical, mechanical and technological characteristics of steel fiber reinforced concrete.

1) Documents regulating the quality requirements for steel fibers of different nomenclature.

2) Guidelines for steel fiber reinforced concrete structures application depending on their type and working conditions of structural concrete of the following types, classes and grades:

a) Heavy concrete of compressive strength classes C16/20; C20/25; C25/30; C30/37; C35/45; C40/50; C45/55; C50/60 [10];

b) Group A fine grained concrete (of normal hardening or heat treated, on the sand with fineness modulus exceeding $\mathrm{M}_{\mathrm{K}}=2.0$ ) of compressive strength classes C16/20; C20/25; C25/30; C30/37; C35/45;

c) Frost resistance marks F50; F75, F100, F150, F200;

g) Waterproofing marks W4, W6, W8.

3) Guidelines for the design of steel fiber reinforced concrete structures and manufacturing techniques for concrete and steel fibers with specific physical, mechanical and technical characteristics.

The guidelines should be aligned with the modern regulations and technical standards of Jordan taking into account the existing level of technical conditions of construction companies, their equipment and the application of new chemical modifiers.

When designing steel fiber reinforced concrete structures resistant to moderately aggressive impact, it is necessary to take into account additional requirements provided by the relevant regulations [11].

Steel fiber reinforced concrete structures should be calculated on the basis of their load-bearing capacity (limit states of the first group) and operability (limit states of the second group) taking into account the peculiarities of steel fiber reinforced concrete structures: reinforcement dispersion; possible thinness of walls; decreased protective layer for rod or wire reinforcement in case of combined reinforcement.

It is mandatory to study strength, hardness and crack resistance of bending and compressed steel reinforced concrete elements prototypes. The effect of volume percent of fiber reinforcement with the minimum and optimum percentage of non-tensioned longitudinal rod reinforcement should also be examined. The effect of fiber reinforcement volume percent in case of local shear (punching) is to be studied separately. The effect of fiber reinforcement volume percent under local compression may also be examined.

Fiber reinforcement reduces the thickness of the subfloor about $20 \%-30 \%$, hence enabling to reduce the consumption of cement and fillers. The use of fiber meshes will enable to save $30 \%-40 \%$ of steel.

It should be noted that industrial floors are subjected to significant loads and the thickness of the concrete subfloor should be increased to ensure the strength of the floor. In this regard, the concrete subfloor is reinforced with a mesh of Ø 10 - $12 \mathrm{~mm}$ rebar S400 (spaced on 150 - $200 \mathrm{~mm}$ in both directions). If the thickness is $100 \mathrm{~mm}$, one mesh is installed, and if the subfloor is thicker, two meshes are installed. The consumption of mesh reinforcement is $7-27 \mathrm{~kg} / \mathrm{m}^{2}$ of the floor (depending on the diameter of rods, the distance between them and the number of meshes).

Application of steel fiber will enable to abandon installment of meshes, thus eliminating time-consuming reinforcement work, and reduce labor cost and the time of floor building and construction in general. 


\section{Conclusions}

The application of fiber is important especially in industrial floors, because of its effect on labor comfort, process quality, and money savings.

The saving of concrete by means of reducing the thickness of the subfloor can reach $20 \%-30 \%$, hence enabling to reduce the consumption of cement and fillers. The abandon of meshes will enable to save $30 \%-40 \%$ of steel.

To implement the existing opportunities to reduce construction costs by using fiber reinforced concrete, it is necessary to provide design and production enterprises in Jordan with regulations on fiber reinforced concrete structures design and construction. In addition the type of fiber to be used in concrete is a further step to be applied in the view of recyclable materials and health-green technologies.

\section{References}

[1] Milani, B. (2005) Building Materials in a Green Economy: Community-Based Strategies for Dematerialization.

[2] Köksal, F., Altun, F., Yiğit, İ. and Şahin, Y. (2008) Combined Effect of Silica Fume and Steel Fiber on the Mechanical Properties of High Strength Concretes. Construction and Building Materials, 22, 1874-1880. http://dx.doi.org/10.1016/j.conbuildmat.2007.04.017

[3] Zhang, M. and Matinlinna, J.P. (2012) E-Glass Fiber Reinforced Composites in Dental Applications. Silicon, 4, 73-78. http://dx.doi.org/10.1007/s12633-011-9075-X

[4] Taylor \& Francis, AKLal (1990) Batiment International. Building Research and Practice, 18, 153-161.

[5] Brandt, A.M. (2008) Fibre Reinforced Cement-Based (FRC) Composites after over 40 Years of Development in Building and Civil Engineering. Composite Structures, 86, 3-9. http://dx.doi.org/10.1016/j.compstruct.2008.03.006

[6] McCarthy, M.A. and Wiggenraad, J.F.M. (2001) Numerical Investigation of a Crash Test of a Composite Helicopter Subfloor Structure. Composite Structure, 51, 345-359. http://dx.doi.org/10.1016/S0263-8223(00)00150-1

[7] Stawiski, B. (2011) Strength of Concrete in Slabs. Investigates along Direction of Concreting, 2, 5.

[8] Wang, Z.-L., Liu, Y.-S. and Shen, R.F. (2008) Stress-Strain Relationship of Steel Fiber-Reinforced Concrete under Dynamic Compression. Construction and Building Materials, 22, 811-819. http://dx.doi.org/10.1016/j.conbuildmat.2007.01.005

[9] Mallick, P.K. (2010) Fiber-Reinforced Composites: Materials, Manufacturing, and Design. CRC Press, Boca Raton.

[10] Kan, Y.C, Pei, K.C. and Chang, Ch.L. (2004) Strength and Fracture Toughness of Heavy Concrete with Various Iron Aggregate Inclusions. Nuclear Engineering and Design, 228, 119-127. http://dx.doi.org/10.1016/j.nucengdes.2003.06.008

[11] Brühwiler, E. and Denarié, E. (2008) Rehabilitation of Concrete Structures Using Ultra-High Performance Fiber Reinforced Concrete. The 2nd International Symposium on Ultra High Performance Concrete, Kassel, 5-7 March 2008, 8 p. 